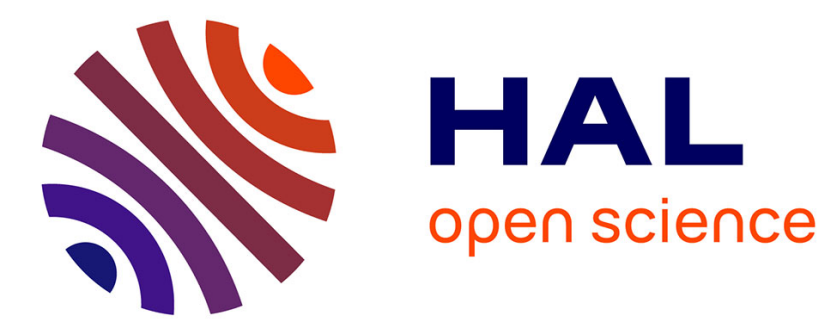

\title{
Gatekeepers Controlling GPCR Export and Function
}

\author{
Stéphane Doly, Stefano Marullo
}

\section{To cite this version:}

Stéphane Doly, Stefano Marullo. Gatekeepers Controlling GPCR Export and Function. Trends in Pharmacological Sciences, 2015, 36 (10), pp.636-644. 10.1016/j.tips.2015.06.007 . hal-02485721

\section{HAL Id: hal-02485721 \\ https://hal.science/hal-02485721}

Submitted on 21 Feb 2020

HAL is a multi-disciplinary open access archive for the deposit and dissemination of scientific research documents, whether they are published or not. The documents may come from teaching and research institutions in France or abroad, or from public or private research centers.
L'archive ouverte pluridisciplinaire HAL, est destinée au dépôt et à la diffusion de documents scientifiques de niveau recherche, publiés ou non, émanant des établissements d'enseignement et de recherche français ou étrangers, des laboratoires publics ou privés. 
2 Gatekeepers controlling GPCR export and function

3

4 Stéphane Doly and Stefano Marullo

5

6 Institut Cochin, INSERM, CNRS, Université Paris Descartes, Sorbonne Paris Cité, 7 Paris, France

8

9

10 Corresponding author: Marullo, S. (stefano.marullo@inserm.fr).

11

12 Keywords: G-protein-coupled receptors (GPCRs); $\gamma$-aminobutyric acid (GABA); 13 GABAB receptor; endoplasmic reticulum gatekeeper; Prenylated Rab Acceptor 14 Family 2 (PRAF2); regulated export 
Regulated export of G protein-coupled receptors (GPCRs) from intracellular

20 stores involves chaperones and escort proteins, which promote their progression to

21 the cell surface, and gatekeepers, which retain them in intracellular compartments.

22 Functional $G A B A_{B}$ receptors, the paradigm of this phenomenon, are composed of

23 GB1 and GB2 subunits forming a hetero-dimer. GB1 is retained in the endoplasmic

24 reticulum (ER) in the absence of GB2. A specific ER-resident gatekeeper, PRAF2, is

25 involved in GB1 retention and prevents its progression into the biosynthetic pathway.

26 GB1 can be released from PRAF2 only upon competitive interaction with GB2.

27 PRAF2 is ubiquitous and belongs to a subgroup of the mammalian Ypt-interacting

28 protein (Yip) family. Several other GPCRs are likely regulated by Yip proteins, which

29 might be involved in the pathophysiology of human diseases that are associated with

30 impaired receptor targeting to the cell surface. 
The number of receptors present at the cell surface that can be reached and

activated by cognate ligands is evidently essential in terms of downstream signaling outputs. Most studies addressing regulation of G protein coupled receptors (GPCRs) have focused on desensitization, the termination of activated receptor signaling, on GPCR endocytosis and recycling, and on the transcriptional control of GPCR-coding genes. Indeed, for a long time it has been assumed that, apart from translation, the only level of regulation of native receptor proteins engaged in the secretory pathway was to successfully pass through quality-control check points, which prevent unfolded proteins to reach the cell surface, redirecting them to the degradation pathway. The regulated export of nascent GPCRs from intracellular stores is a concept that has emerged recently. It is based on the observation that in primary cells several GPCRs are only marginally expressed at the cell surface, whereas abundant stores exist both in the endoplasmic recticulum (ER) and in the Golgi apparatus. One of the pioneering observations of this phenomenon was that in both primary and transfected cells, an important proportion of the PAR1 thrombin receptor was intracellular and co-localized with Golgi markers. Whereas surface PAR1 was internalized and subsequently targeted to lysosomes upon thrombin activation, the intracellular pool was translocated to the plasma membrane, leading to the recovery of thrombin responsiveness [1]. Subsequently, a series of independent observations coincided to suggest that the regulated export of GPCRs from the Golgi apparatus and the ER was actually a much wider phenomenon than previously anticipated (see $[2,3]$ for an historical overview). It also appeared that receptors are released from intracellular compartments upon appropriate extracellular signals and/or association 
key issues of this novel paradigm of regulation, such as the identification of the molecular tethers that retain GPCRs in the intracellular compartments or the characterization of the mechanisms of their release from these compartments remained poorly understood.

62 investigated GPCRs over the past three decades, because of the very unusual regulation of its cell surface export. It belongs to the class-C family of GPCRs, also comprising the metabotropic glutamate receptor, the calcium sensing receptor and the taste $T 1 R$, which is characterized by a large extracellular Venus flytrap (VFT) domain involved in ligand recognition. Together with the ionotropic GABAA receptor, $\mathrm{GABA}_{B}$ responds to the $\gamma$-aminobutyric acid (GABA), the major inhibitory neurotransmitter in the central nervous system (CNS). Presynaptic GABAB receptor reduces neurotransmitter release, whereas postsynaptic receptor causes hyperpolarization of neurons [4]. By inhibiting synaptic transmission, GABA $\mathrm{B}$ plays a key role in modulating neuronal activity and impaired function of GABAB has been associated with multiple neurological and psychiatric diseases [5-7]. Peripheral $\mathrm{GABA}_{B}$ receptors have also been identified, particularly in the gastrointestinal tract [8]. Baclofen, а GABAв agonist, is currently used to treat spasticity of various pathophysiological origins and alcoholism, whereas peripherally-restricted $\mathrm{GABA}_{B}$ agonists devoid of CNS side effects are under investigation to treat gastroesophageal reflux disease [9]. In addition, recent studies indicate that peripheral $\mathrm{GABA}_{\mathrm{B}}$ receptors might represent a pharmacological target for tumor therapy [10] and for improving pancreatic $\beta$-cell survival [11]. 
In addition to its functional roles, the $\mathrm{GABA}_{\mathrm{B}}$ receptor occupies a special position among GPCRs, since several paradigms established for the GPCR family are based on pioneering studies based on $\mathrm{GABA}_{\mathrm{B}}$ as receptor model. Unlike the other class-C GPCRs, which form homo-dimers, functional GABA ${ }_{B}$ receptors are obligate hetero-dimers made of one GB1 and one GB2 subunit [12-14]. Mice lacking GB1 do not exhibit any detectable electrophysiological, biochemical, or behavioral response to agonists $[15,16]$. Similarly, GB2 ${ }^{-/-}$mice display spontaneous seizures, hyperalgesia, hyperlocomotor activity, and severe memory impairment, analogous to GB1--- mice, although atypical electrophysiological $\mathrm{GABA}_{\mathrm{B}}$ responses are present in a few areas of the brain [17]. The loss of normal $G A B A_{B}$ function in vivo and in vitro when either GB1 or GB2 is missing is explained by the particular distribution of key functional tasks between receptor subunits. Indeed, GB1 is responsible for ligand recognition through its VFT domain, whereas GB2 does not bind to any known $\mathrm{GABA}_{\mathrm{B}}$ ligand [18]; its VFT domain only behaves like an allosteric modulator of the GB1 VFT, enhancing its agonist affinity [19]. The transmembrane region of GB2, instead, is responsible for G-protein coupling [20, 21] and also facilitates cell surface expression of GB1 [22].

\section{A missing mechanistic aspect in the regulated delivery of $G A B A_{B}$ to the cell surface}

The cell surface density of functional hetero-dimeric $G A B A B$ receptors is controlled by a unique mechanism of delivery from the biosynthetic compartments to the plasma membrane. Early studies reported that recombinant GB1 subunits fail to reach the cell surface when expressed in heterologous systems or overexpressed in ganglion neurons [23]. The explanation of this phenomenon is that GB1 is retained in the ER and does not reach the cell surface in the absence of GB2 [12-14]. 
108 Subsequent investigations identified an arginine based ER retention/retrieval "RSRR"

109 signal in the carboxyterminal tail of GB1 [22]. This signal is a variant of a more 110 general RXR motif (two arginine residues separated by any aminoacid) found in a 111 variety of ER-retained subunits of multimeric protein complexes, such as the 112 octameric ATP-sensitive $\mathrm{K}^{+}$channels [24] or the $\mathrm{N}$-methyl-D-aspartate (NMDA) 113 receptors [25]. The alanine substitution of the arginine residues of the RXR motif 114 allowed the corresponding GB1-AXA subunit to reach the cell surface even in the 115 absence of GB2. It was then proposed that only the shielding of this retention signal 116 via a coiled-coil interaction with the C-terminus of GB2 might allow the GB1-GB2 117 hetero-dimer to progress along the secretory pathway delivering functional GABAB 118 receptors to the cell surface [22]. A second key di-leucine motif was subsequently 119 identified upstream of the RXR motif in the carboxyterminal tail of GB1, which also 120 controls the cell surface export of the receptor in hippocampal neurons [26]. It was 121 observed that in the absence of co-expressed GB2 the GB1-AA-ASA mutant, 122 encompassing the mutation of both the RXR and the di-leucine motifs, was much 123 better exported to the cell surface than the wild type GB1 or the single GB1-ASA 124 mutant. Because the GB1-ASA mutant was partially accumulated within the trans125 Golgi network (TGN) and because this accumulation was rescued by the double 126 mutation, a two-step sequential mechanism regulating $\mathrm{GABA}_{B}$ export at distinct 127 checkpoints in the ER and the Golgi was postulated [26]. However, a missing 128 mechanistic aspect of the complex regulation of the $\mathrm{GABA}_{\mathrm{B}}$ hetero-dimer delivery to 129 the cell surface has remained for long time: the nature of the tether(s) that in the 130 absence of association with GB2 retain(s) GB1 in the ER and in the TGN. This tether, 131 which is responsible for the predominant ER localization of the GB1 subunit in 132 primary neurons [27], might play an essential role in GABAв receptor physiology. 
The coiled-coil domain of the carboxyterminal tail of the GB1, containing both

$\mathrm{RXR}$ and LL motifs, is presumably involved in the interaction with a putative ERresident "gatekeeper", which regulates the delivery of the GABA ${ }_{B}$ heterodimer to the 137 cell surface.

During the past ten years, multiple GB1 interacting proteins have been reported, which regulate $G A B A_{B}$ expression in some way, often interacting with the GB1 coiled-coil domain. However, under physiological conditions, none of these proteins appears to retain GB1 in the ER via a direct interaction. The cytoplasmic scaffolding protein 14-3-3 $\square$ can dissociate GABAв receptor hetero-dimers present at

143 the plasma membrane [28] [29] and does not interact with GB1 in the ER [29, 30].

144 The cytoplasmic coatomer COP1 might rather be involved in the retrieval of monomeric GB1 from the cis-Golgi to the ER [30]. Msec-7, an ARF1, 3,6 guaninenucleotide exchange factor, which specifically interacts with the GB1 tail di-leucine motif, enhances $G A B A_{B}$ trafficking from the Golgi to the cell surface, after its exiting from the ER. GISP, another scaffolding protein of the AKAP family, was reported to enhance $G A B A B$ receptor function possibly by slowing down receptor desensitization and lysosomal sorting [31]. The transcription factor CCAAT/enhancer-binding protein

151 homologous protein CHOP is markedly overexpressed upon ER stress, for example 152 during cerebral ischemia. In this context, CHOP interacts with both GB1 and GB2 in 153 the ER preventing or disrupting hetero-dimerization, and forward trafficking of the 154 receptors to the plasma membrane [32]. Because of its marginal level of expression 155 under physiological conditions and the fact that it is not an ER resident protein, it is 156 unlikely that $\mathrm{CHOP}$ is responsible for GB1 retention in this compartment. In 157 conclusion, none of the GB1-interacting partners identified so far displayed the 
expected biochemical and/or functional properties for a GB1 gatekeeper in the ER.

Ultimately, Prenylated Rab Acceptor Family 2 (PRAF2), an ER-resident 4-

160 transmembrane domain protein, was identified recently as a major GABA

161 gatekeeper [27]. PRAF2 interacts with the GB1 subunit of GABA $B$ but not with the

162 GB2 subunit, this interaction involving both RXR and LL motifs of the carboxy163 terminal tail of GB1. PRAF2-bound GB1 remains trapped in the ER and its release 164 only occurs upon competitive displacement of PRAF2 by GB2. Thus, the local concentration of PRAF2, relative to that of GB1 and GB2, tightly controls cell surface receptor density and thus impacts on $\mathrm{GABA}_{B}$ function in neurons or in transfected cells (Figure 1). Interestingly, minor (less than two-fold) modifications of PRAF2 concentration in a localized region of mouse brain, the ventral tegmental area (VTA), caused major behavioral effects in animal models (Figure 2). These effects could be attributed to the resulting local changes in cell surface $G A B A_{B}$ receptor expression [27].

Although identified ten years ago as an interacting partner of the CCR5 chemokine receptor in a two-hybrid screen [33], PRAF2 had no clearly identified functions so far; it was found enriched in human brain [34], overexpressed in multiple

175 cancers [35, 36] being correlated with poor prognosis [37]. PRAF2 belongs to a

176 family of three ubiquitous 4-transmembrane domain proteins [35], localized either in 177 the ER (PRAF2 and 3) or in the Golgi apparatus (PRAF1) (Table 1). Similarly to the

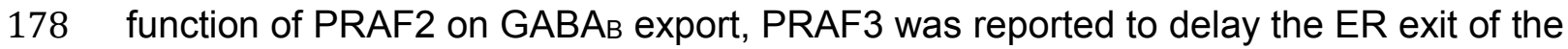
$179 \mathrm{Na}^{+}$-dependent glutamate transporter Excitatory Amino-Acid Carrier 1 (EAAC1) [38, 180 39]. PRAF1, the first identified member of the PRAF family, was proposed to activate 181 the dissociation of prenylated Rab proteins from the GDP dissociation inhibitor GDI, 182 thus facilitating the association of prenylated Rabs with target Golgi membranes [40]. 
183 The property of PRAF1 (also known as PRA1) to interact with numerous prenylated

184 Rab GTPases [41] led to classify PRAF family members among mammalian Yips 185 (Ypt-interacting proteins, Ypts being the yeast Rab homologues) [42]. Mammalian 186 Yips (Table 1) also comprise 5-transmembrane proteins of the YIPF (YIP1 domain 187 family, 1 to 7 ) and YIF1 (Yip1 interacting factor homolog A and B) groups, as well as 188 the 2-transmembrane protein family REEP (receptor expression enhancing proteins, 1891 to 6$)$. Collectively, Yips are involved in the control of cellular vesicle trafficking 190 between the ER and the Golgi network, REEPs displaying the additional function of 191 adapter proteins for cargo receptors [43].

PRAF gatekeepers might regulate other GPCRs in various tissues Although the mechanistic aspects of PRAF2-dependent regulation have only 195 been elucidated for the $\mathrm{GABA}_{B}$ receptor, it is quite plausible that PRAFs might 196 collectively regulate several other GPCRs. Indeed, as indicated above, PRAF2 was 197 originally identified in two-hybrid screens as an interaction partner of the chemokine 198 CCR5 receptor, regulating in some way its membrane localization [33]. PRAF3, on 199 the other hand, was reported to restrict the subcellular localization of the $\beta 2$ 200 adrenoceptor and the D2-dopaminergic receptor to the ER [39]. In preliminary 201 studies, we found that PRAF gatekeepers associate (in BRET and co-IP 202 experiments) with other chemokine receptors, such as CCR2 and CCR7, and with 5203 HT2 serotoninergic receptors (unpublished data). Finally, both PRAF2 [35] and 204 PRAF3 [38, 44] are expressed in most tissues, where they coexist with multiple 205 GPCRs.

In addition to the GABAB receptor, several other GPCRs undergo regulated 207 translocation to the plasma membrane from ER or Golgi stores [2], where they might 
208 possibly be retained by PRAFs or PRAF-like gatekeepers. In tubular renal cells, 209 intracellular dopamine D1 receptors are recruited to the plasma membrane by 210 agonist activation of cell surface receptors [45] or via atrial natriuretic peptide211 dependent heterologous activation [46]. Similarly, the sustained stimulation of $\mu$ 212 opioid receptors can redistribute $\delta$-opioid receptors (DOP) to the plasma membrane 213 in vivo, improving DOP-dependent anti-nociceptive effects [47]. Several other 214 GPCRs poorly expressed at the plasma membrane, such as the odorant receptors 215 [48], the human GnRH receptor [49], the $\alpha_{1 \mathrm{D}}$-adrenoceptor [50], the LH receptor [51], 216 and the CCR5 chemokine receptor [52] represent other candidates for gatekeeper217 controlled translocation to the cell surface.

218 Although the functional organization of the $\mathrm{GABA}_{\mathrm{B}}$ receptor as an obligatory 219 hetero-dimer is quite unique among GPCRs, it is currently admitted that most if not 220 all the receptors of this family are expressed at the cell surface as homo-dimers [53].

221 Several observations indicate that, among other functions, homo-dimerization might 222 also contribute to quality control of newly synthesized receptors [54]. An interesting 223 hypothesis in this context is that the homo-dimerization of two correctly folded 224 receptors might displace the interaction with resident gatekeepers similarly to hetero225 dimerization. The GABAв model might thus represent an atypical example of a more 226 general phenomenon.

Potential involvement of PRAFs in human disease

Similar or even larger changes of PRAF2 than those we observed inducing phenotypic effects in animals can either be detected physiologically, during neuronal differentiation for example, or in pathological samples, such as human cancer tissues

232 [36] and brain areas of persons deceased after excessive alcohol intake [55]. These 
233 findings indicate a potential causative connection between the concentration of PRAF

234 gatekeepers and pathological changes in humans. In addition, although not

235 functionally investigated so far, several variants of PRAF2 have been reported (see

236 the link www.nextprot.org/db/entry/NX_O60831/sequence), which are located in

237 various domains of the protein, including within the regions that are likely at the

238 interface with GB1 [27]. Therefore, both qualitative and quantitative changes of these

239 gatekeepers might have an impact on GPCR receptivity and consequently be

240 involved in human disease.

241 Finally, the new concept of GPCR gatekeepers might lead to revisit already

242 known pathophysiological mechanisms. For example, in the kidney, where both

243 PRAF2 and PRAF3 are present, variants of the V2 vasopressin receptor (V2R) are

244 poorly expressed at the cell surface of tubular cells, impairing water reabsorption and

245 causing nephrogenic diabetes insipidus [56]. Membrane-permeable pharmacological

246 chaperones have been reported, which bind to intracellular receptors and facilitate

247 their cell surface export, with a partial rescue of receptor function and of excessive

248 diuresis [57]. It would be interesting in this context to examine the association of wild-

249 type and variant V2Rs with PRAFs, as an increased affinity of the variant receptor for

250 its cognate gatekeeper, might well explain its retention in the ER.

\section{Concluding remarks}

253 The identification of the resident gatekeeper, which retains the GB1 subunit of the

$254 \mathrm{GABA}_{B}$ receptor in the ER upon interaction with both the di-leucine and RXR motifs

255 of the carboxyterminal tail of GB1 until it is displaced by the GB2 subunit, completes

256 the picture of the complex mechanism regulating the delivery of functional GABA

257 receptors to the cell surface. PRAFs were already reported to interact with and/or 
258 regulate several other GPCRs and plasma membrane transporters. In addition, 259 among mammalian Yips, REEP family proteins, which were initially considered as 260 GPCR escorts, might also behave like gatekeepers regulating the ER exit of some 261 receptors [43]. Therefore, for many GPCRs and more generally for multi-span 262 plasma membrane proteins, the gatekeeper-regulated release from intracellular 263 stores might become a new parameter to be considered when analyzing the 264 effectiveness of receptor response in physiological conditions, during agonist 265 treatment or in the case of pathological export defects. These considerations raise a 266 number of new questions* in the field, such as how gatekeepers are themselves

267 regulated, how many other GPCRs are potentially regulated by these types of 268 gatekeepers, in which organs and for which functions, and are changes in 269 gatekeeper concentration or point mutations at the interface with receptors involved 270 in human disease. We anticipate that these questions are sufficiently important to 271 promote additional investigations in the years to come.

273 Acknowledgements

274 We thank Dr Hervé Enslen and Dr Mark GH Scott of our laboratory for having 275 reviewed the manuscript. The research of our laboratory is supported by grants of the 276 Fondation pour la Recherche Médicale And Ligue Contre le Cancer, Comité de 277 l'Oise. 


\section{References}

2801 Hein, L. et al. (1994) Intracellular targeting and trafficking of thrombin 281 receptors. A novel mechanism for resensitization of a $G$ protein-coupled 282 receptor. J Biol Chem 269, 27719-27726

2832 Achour, L. et al. (2008) An escort for G Protein Coupled Receptors to find their 284 path: implication for regulation of receptor density at the cell surface. Trends 285 Pharmacol Sci 29, 528-535

286

3 Shirvani, H. et al. (2012) Regulated GPCR Trafficking to the Plasma 287 Membrane: General Issues and the CCR5 Chemokine Receptor Example. Sub-cellular biochemistry $63,97-111$

289

4 Bettler, B. et al. (2004) Molecular structure and physiological functions of 290 GABA(B) receptors. Physiol Rev 84, 835-867

2915 Gambardella, A. et al. (2003) Gaba-B receptor 1 polymorphism (G1465A) is 292 associated with temporal lobe epilepsy. Neurology 60, 560-563

2936 Tyacke, R.J. et al. (2010) GABAB receptors in addiction and its treatment. Adv 294 Pharmacol 58, 373-396

2957 Cryan, J.F. and Slattery, D.A. (2010) GABAB Receptors and Depression: 296 Current Status. Adv Pharmacol 58, 427-451

2978 Hyland, N.P. and Cryan, J.F. (2010) A Gut Feeling about GABA: Focus on 298 GABA(B) Receptors. Front Pharmacol 1, 124

2999 Lehmann, A. et al. (2010) GABAB receptor agonism as a novel therapeutic 300 modality in the treatment of gastroesophageal reflux disease. Adv Pharmacol $58,287-313$ 
30210 Zhang, X. et al. (2013) Expression of gamma-aminobutyric acid receptors on 303 neoplastic growth and prediction of prognosis in non-small cell lung cancer. $J$ $304 \quad$ Transl Med 11, 102

30511 Tian, J. et al. (2013) gamma-Aminobutyric acid regulates both the survival and 306 replication of human beta-cells. Diabetes 62, 3760-3765

30712 Jones, K.A. et al. (1998) GABA(B) receptors function as a heteromeric 308 assembly of the subunits GABA(B)R1 and GABA(B)R2. Nature 396, 674-679 30913 Kaupmann, K. et al. (1998) GABA(B)-receptor subtypes assemble into 310 functional heteromeric complexes. Nature 396, 683-687.

31114 White, J.H. et al. (1998) Heterodimerization is required for the formation of a 312 functional GABA(B) receptor. Nature 396, 679-682.

31315 Prosser, H.M. et al. (2001) Epileptogenesis and enhanced prepulse inhibition 314 in GABA(B1)-deficient mice. Mol Cell Neurosci 17, 1059-1070

31516 Schuler, V. et al. (2001) Epilepsy, hyperalgesia, impaired memory, and loss of 316 pre- and postsynaptic $\mathrm{GABA}(\mathrm{B})$ responses in mice lacking $\mathrm{GABA}(\mathrm{B}(1))$. $317 \quad$ Neuron $31,47-58$

31817 Gassmann, M. et al. (2004) Redistribution of GABAB(1) protein and atypical 319 GABAB responses in GABAB(2)-deficient mice. J Neurosci 24, 6086-6097

32018 Kniazeff, J. et al. (2002) No ligand binding in the GB2 subunit of the GABA(B) 321 receptor is required for activation and allosteric interaction between the $322 \quad$ subunits. J Neurosci 22, 7352-7361

32319 Galvez, T. et al. (2001) Allosteric interactions between GB1 and GB2 subunits 324 are required for optimal GABA(B) receptor function. EMBO J 20, 2152-2159 
32520 Margeta-Mitrovic, M. et al. (2001) Function of GB1and GB2 subunits in G 326 protein coupling of GABA(B) receptors. . Proc. Natl Acad. Sci. USA 98, $327 \quad 14649-14654$

32821 Robbins, M.J. et al. (2001) GABA(B2) is essential for G-protein coupling of the 329 GABA(B) receptor heterodimer. J Neurosci 21, 8043-8052

33022 Margeta-Mitrovic, M. et al. (2000) A trafficking checkpoint controls GABA(B) 331 receptor heterodimerization. Neuron 27, 97-106.

33223 Couve, A. et al. (1998) Intracellular retention of recombinant GABAB $333 \quad$ receptors. J Biol Chem 273, 26361-26367

33424 Zerangue, N. et al. (1999) A new ER trafficking signal regulates the subunit 335 stoichiometry of plasma membrane K(ATP) channels. Neuron 22, 537-548

33625 Scott, D.B. et al. (2001) An NMDA receptor ER retention signal regulated by 337 phosphorylation and alternative splicing. J Neurosci 21, 3063-3072

33826 Restituito, S. et al. (2005) Multiple motifs regulate the trafficking of GABA(B) 339 receptors at distinct checkpoints within the secretory pathway. Mol Cell $340 \quad$ Neurosci $28,747-756$

34127 Doly, S. et al. (2015) GABAB receptor cell surface export and inhibitory neurotransmission is controlled by an endoplasmic reticulum gatekeeper $\mathrm{Mol}$ $343 \quad$ Psychiatry, doi: 10.1038/mp.2015.1072. [Epub ahead of print]

34428 Couve, A. et al. (2001) Association of GABA(B) receptors and members of the $345 \quad$ 14-3-3 family of signaling proteins. Mol Cell Neurosci 17, 317-328

34629 Laffray, S. et al. (2012) Impairment of GABAB receptor dimer by endogenous 14-3-3zeta in chronic pain conditions. EMBO J 31, 3239-3251 
34830 Brock, C. et al. (2005) Assembly-dependent surface targeting of the 349 heterodimeric GABAB Receptor is controlled by COPI but not 14-3-3. Mol. $350 \quad$ Biol. Cell 16, 5572-5578

35131 Kantamneni, S. et al. (2009) GISP increases neurotransmitter receptor 352 stability by down-regulating ESCRT-mediated lysosomal degradation. $353 \quad$ Neuroscience letters 452, 106-110

35432 Maier, P.J. et al. (2014) Ischemia-like oxygen and glucose deprivation 355 mediates down-regulation of cell surface $y$-aminobutyric acidB receptors via 356 the endoplasmic reticulum (ER) stress-Induced transcription factor 357 CCAAT/enhancer-binding protein (C/EBP)-homologous protein (CHOP). J Biol $358 \quad$ Chem 289, 12896-12907

35933 Schweneker, M. et al. (2005) JM4 is a four-transmembrane protein binding to 360 the CCR5 receptor. FEBS Lett 579, 1751-1758

36134 Koomoa, D.L. et al. (2008) Expression profile of PRAF2 in the human brain 362 and enrichment in synaptic vesicles. Neurosci Lett 436, 171-176

36335 Fo, C.S. et al. (2006) Genomic organization, expression profile, and 364 characterization of the new protein PRA1 domain family, member 2 (PRAF2). $365 \quad$ Gene 371, 154-165

$36636 \quad$ Borsics, T. et al. (2010) Subcellular distribution and expression of prenylated 367 Rab acceptor 1 domain family, member 2 (PRAF2) in malignant glioma: 368 Influence on cell survival and migration. Cancer Sci 101, 1624-1631

36937 Yco, L.P. et al. (2013) PRAF2 stimulates cell proliferation and migration and $370 \quad$ predicts poor prognosis in neuroblastoma. Int J Oncol 42, 1408-1416

37138 Lin, C.I. et al. (2001) Modulation of the neuronal glutamate transporter EAAC1 372 by the interacting protein GTRAP3-18. Nature 410, 84-88 
37339 Ruggiero, A.M. et al. (2008) The endoplasmic reticulum exit of glutamate 374 transporter is regulated by the inducible mammalian Yip6b/GTRAP3-18 $375 \quad$ protein. J Biol Chem 283, 6175-6183

37640 Sivars, U. et al. (2003) Yip3 catalyses the dissociation of endosomal Rab-GDI complexes. Nature 425, 856-859

37841 Lin, J. et al. (2001) Membrane topography and topogenesis of prenylated Rab acceptor (PRA1). J Biol Chem 276, 41733-41741

38042 Pfeffer, S. and Aivazian, D. (2004) Targeting rab GTPases to distinct 381 membrane compartments. Nat Rev Mol Cell Biol 5, 886-896

38243 Björk, S. et al. (2013) REEPs are membrane shaping adapter proteins that 383 modulate specific g protein-coupled receptor trafficking by affecting ER cargo $384 \quad$ capacity. PLoS One 8, e76366

38544 Abdul-Ghani, M. et al. (2001) PRA isoforms are targeted to distinct membrane 386 compartments. J Biol Chem 276, 6225-6233

38745 Brismar, H. et al. (1998) Dopamine-induced recruitment of dopamine D1 receptors to the plasma membrane. Proc Natl Acad Sci U S A 95, 5573-5578

38946 Holtback, U. et al. (1999) Receptor recruitment: a mechanism for interactions between G protein-coupled receptors. Proc Natl Acad Sci U S A 96, 72717275

39247 Cahill, C.M. et al. (2007) Trafficking of delta-opioid receptors and other G393 protein-coupled receptors: implications for pain and analgesia. Trends $394 \quad$ Pharmacol Sci 28, 23-31

39548 Saito, H. et al. (2004) RTP family members induce functional expression of mammalian odorant receptors. Cell 119, 679-691 
39749 Janovick, J.A. et al. (2006) Regulation of G protein-coupled receptor trafficking 398 by inefficient plasma membrane expression: molecular basis of an evolved 399 strategy. J Biol Chem 281, 8417-8425

$40050 \quad$ Uberti, M.A. et al. (2005) Heterodimerization with beta2-adrenergic receptors 401 promotes surface expression and functional activity of alpha1D-adrenergic 402 receptors. J Pharmacol Exp Ther 313, 16-23

40351 Pietila, E.M. et al. (2005) Inefficient maturation of the rat luteinizing hormone 404 receptor. A putative way to regulate receptor numbers at the cell surface. $J$ $405 \quad$ Biol Chem 280, 26622-26629

40652 Achour, L. et al. (2009) CD4 - CCR5 interaction in intracellular compartments 407 contributes to receptor expression at the cell surface. Blood 113, 1938-1947

40853 Rivero-Muller, A. et al. (2013) Di/oligomerization of GPCRs-mechanisms and 409 functional significance. Prog Mol Biol Trans/ Sci 117, 163-185

41054 Bulenger, S. et al. (2005) Emerging role of homo- and heterodimerization in G411 protein-coupled receptor biosynthesis and maturation. Trends Pharmacol Sci $412 \quad 26,131-137$

41355 Enoch, M.A. et al. (2013) A factor analysis of global GABAergic gene 414 expression in human brain identifies specificity in response to chronic alcohol $415 \quad$ and cocaine exposure. PLoS One 8, e64014

41656 Morello, J.P. and Bichet, D.G. (2001) Nephrogenic diabetes insipidus. Annu 417 Rev Physiol 63, 607-630

41857 Bernier, V. et al. (2004) Pharmacological chaperone action on G-protein419 coupled receptors. Curr Opin Pharmacol 4, 528-533

42058 Tang, B.L. et al. (2001) A membrane protein enriched in endoplasmic 421 reticulum exit sites interacts with COPII. J Biol Chem 276, 40008-40017 
42259 Heidtman, M. et al. (2003) A role for Yip1p in COPIl vesicle biogenesis. J Cell $423 \quad$ Biol $163,57-69$

42460 Voeltz, G.K. et al. (2006) A class of membrane proteins shaping the tubular 425 endoplasmic reticulum. Cell 124, 573-586

42661 Behrens, M. et al. (2006) Members of RTP and REEP gene families influence 427 functional bitter taste receptor expression. J. Biol Chem 281, 20650-20659

42862 llegems, E. et al. (2010) REEP2 enhances sweet receptor function by 429 recruitment to lipid rafts. J Neurosci 30, 13774-13783

43063 Schlaitz, A.L. et al. (2013) REEP3/4 ensure endoplasmic reticulum clearance 431 from metaphase chromatin and proper nuclear envelope architecture. Dev Cell $432 \quad 26,315-323$

43364 Wu, Y. et al. (2011) JWA regulates chronic morphine dependence via the 434 delta opioid receptor. Biochem Biophys Res Commun 409, 520-525

43565 Shakoori, A. et al. (2003) Identification of a five-pass transmembrane protein 436 family localizing in the Golgi apparatus and the ER. Biochem Biophys Res Commun 312, 850-857

43866 Tanimoto, K. et al. (2011) Characterization of YIPF3 and YIPF4, cis-Golgi $439 \quad$ localizing Yip domain family proteins. Cell Struct Funct 36, 171-185

44067 Kuijpers, M. et al. (2013) The ALS8 protein VAPB interacts with the ER-Golgi 441 recycling protein YIF1A and regulates membrane delivery into dendrites.

$442 \quad E M B O J 32,2056-2072$

44368 Carrel, D. et al. (2008) Targeting of the 5-HT1A serotonin receptor to neuronal 444 dendrites is mediated by Yif1B. J Neurosci 28, 8063-8073 
44569 Barone, V. et al. (2015) Yip1B isoform is localized at ER-Golgi intermediate 446 and cis-Golgi compartments and is not required for maintenance of the Golgi $447 \quad$ structure in skeletal muscle. Histochem Cell Biol 143, 235-243

448

449

450

451 


\section{Figure Legends}

Figure 1. Retention and release of GB1 is governed by the relative concentrations of GB1, GB2 and PRAF2. (A) In neurons GB2 and PRAF2 compete for binding to GB1. Hetero-dimerization of GB1 with GB2 allows the release from the $E R$ and the export of the functional $G A B A_{B}$ receptor to the cell surface. Association with PRAF2 maintains the GB1 subunit in the ER. (B) The heterologous expression of GB1 in transfected cells, which contains endogenous PRAF2 and no GB2, reproduces the conditions existing in neurons of GB2-KO mice. GB1 is retained in the ER and no GABA binding sites can be measured at the cell surface. (C) If PRAF2 concentration is decreased (i.e. siRNA treatment) in transfected cells expressing exogenous GB1, or GB1 markedly overexpressed, the available PRAF2 molecules are completely saturated by GB1. Unbound GB1 is not retained and can reach the cell surface. Surface GABA binding sites can be measured in these conditions corresponding to surface GB1. However, because of the absence of GB2 subunits, functional $G A B A_{B}$ receptors capable of transducing a signal are lacking.

Figure 2. Locomotor activity in mice expressing exogenous PRAF2 in the VTA.

470 To examine whether perturbing the stoichiometry of GB1, GB2 and PRAF2 might 471 affect GABA $\mathrm{B}$-dependent regulations in vivo, PRAF2 concentration was enhanced (24723 folds) in the ventral tegmental area (VTA), a brain area containing GAGA ${ }_{B}$ 473 expressing neuron, by stereotaxic injection of an adenovirus driving the local 474 expression of the exogenous gatekeeper. Activation of the dopaminergic circuits from 475 the VTA to the nucleus accumbens (NAcc) produces locomotor activity, which is 476 inhibited by GABAв activation (blue-boxed panels). In case of loss of surface GABAв 
477 receptors in VTA dopaminergic neurons, caused by PRAF2-mediated GB1 retention, 478 dopamine release is increased and locomotor activity enhanced (red-boxed panels). 479 The unilateral change of PRAF2 concentration in the VTA led to a remarkable 480 contralateral turning phenotype (see supplemental videos in [26]).

481 


\begin{tabular}{|c|c|c|c|c|c|c|c|}
\hline Name & Other Names & $\begin{array}{c}\text { Yeast } \\
\text { homologue }\end{array}$ & $\begin{array}{l}\text { Gene } \\
\text { ID }\end{array}$ & $\begin{array}{c}\text { AA } \\
\text { number }\end{array}$ & TM & $\begin{array}{l}\text { Localization / } \\
\text { Functions }\end{array}$ & $\begin{array}{c}\text { Regulated } \\
\text { Receptors/Transporters }\end{array}$ \\
\hline $\begin{array}{l}\text { YIPF5 (Yip1 } \\
\text { domain } \\
\text { family, } \\
\text { member 5) }\end{array}$ & $\begin{array}{c}\text { Yip1; YPT-interacting } \\
\text { protein 1A; Yip1A; } \\
\text { FinGER5; SMAP5; } \\
\text { SB140 }\end{array}$ & Yip1p & 81555 & 257 & 5 & $\begin{array}{l}\text { ER exit sites, ER } \\
\text { to Golgi } \\
\text { Transport }[58,59]\end{array}$ & \\
\hline $\begin{array}{l}\text { REEP1 } \\
\text { (receptor } \\
\text { expression- } \\
\text { enhancing } \\
\text { protein1) }\end{array}$ & Yip2a & Yip2, Yop1 & 65055 & 201 & 2 & $\begin{array}{l}\text { ER morphology } \\
\text { and dynamics[60] }\end{array}$ & $\begin{array}{c}\text { Odorant receptors [48]; } \\
\text { bitter taste receptor [61]; } \\
\quad \alpha 2_{C} A R[43]\end{array}$ \\
\hline REEP2 & Yip2d & & 51308 & 252 & 2 & ER resident [43] & $\begin{array}{c}\text { Odorant receptors [48]; } \\
\text { sweet receptor [62]; } \\
\alpha 2_{c} A R[43]\end{array}$ \\
\hline REEP3 & Yip2b & & 221035 & 255 & 2 & $\begin{array}{l}\text { clearing ER from } \\
\text { metaphase } \\
\text { chromatin [63] }\end{array}$ & Odorant receptors [48] \\
\hline REEP4 & Yip2c & & 80346 & 257 & 2 & $\begin{array}{l}\text { clearing ER from } \\
\text { metaphase } \\
\text { chromatin [63] }\end{array}$ & \\
\hline REEP5 & Yip2e & & 7905 & 189 & 2 & & \\
\hline REEP6 & Yip2f & & 92840 & 184 & 2 & ER resident [43] & $\alpha 2_{C} \mathrm{AR}[43]$ \\
\hline RABAC1, & Yip3; PRA1, PRAF-1 & Yip3 & 10567 & 185 & 4 & $\begin{array}{l}\text { Golgi [44]; } \\
\text { Prenylated Rab } \\
\text { acceptor [40] }\end{array}$ & \\
\hline PRAF-2 & Yip6a; JM4 & & 11230 & 178 & 4 & ER [35] & CCR5 [33], GABA \\
\hline ARL6IP5 & $\begin{array}{c}\text { JWA; PRA2; jmx; } \\
\text { hp22; PRAF-3; } \\
\text { DERP11; HSPC127; } \\
\text { addicsin; GTRAP3- } \\
\text { 18; Yip6b }\end{array}$ & & 10550 & 188 & 4 & $\begin{array}{l}\text { ER [44]; control } \\
\text { of ER exit [39] }\end{array}$ & $\begin{array}{c}\text { EAAC1 [38]; EAAT1,2,4; } \\
\beta_{2} A R ; \alpha 2_{B} A R ; D_{2} R[39] ; \\
\text { DOR [64] }\end{array}$ \\
\hline YIPF6 & $\begin{array}{c}\text { FinGER6; } \\
\text { MGC21416; Yip4 }\end{array}$ & Yip4 & 286451 & 237 & 5 & Golgi [65] & \\
\hline YIPF1 & $\begin{array}{c}\text { FinGER1; } \\
\text { DJ167A19.1, Yip5a }\end{array}$ & Yip5 & 54432 & 306 & 5 & Golgi [65] & \\
\hline YIPF3 & $\begin{array}{l}\text { KLIP1; FinGER3; } \\
\text { C6orf109; } \\
\text { dJ337H4.3; Yip5b }\end{array}$ & & 25844 & 350 & 5 & $\begin{array}{c}\text { Cis-Golgi [66] } \\
\text { [65] }\end{array}$ & \\
\hline YIPF2 & FinGER2; Yip5c & & 78992 & 316 & 5 & Golgi [65] & \\
\hline $\begin{array}{l}\text { YIF1A (Yip1 } \\
\text { interacting } \\
\text { factor } \\
\text { homolog A) }\end{array}$ & $\begin{array}{c}\text { 54TM; YIF1; YIF1P; } \\
\text { FinGER7 }\end{array}$ & Yif1 & 10897 & 293 & 5 & $\begin{array}{l}\text { ER to Golgi } \\
\text { transport; delivery } \\
\text { into dendrites [67] }\end{array}$ & \\
\hline YIF1B & FinGER8 & & 90522 & 314 & 5 & $\begin{array}{c}\text { Golgi [65]; ER- } \\
\text { Golgi trafficking } \\
\text { [68] }\end{array}$ & 5-HT1AR [68] \\
\hline YIPF7 & FinGER9, Yip1B & & 285525 & 280 & 5 & $\begin{array}{c}\text { ERGIC; cisGolgi; } \\
\text { skeletal muscle } \\
\text { [69] }\end{array}$ & \\
\hline YIPF4 & FinGER4; Nbla11189 & & 84272 & 244 & 5 & Cis-Golgi [66] & \\
\hline
\end{tabular}


*Outstanding Questions Box

485

486 - How many GPCRs undergo a similar regulation of their cell surface export by

487 PRAFs, other Yips or functionally equivalent additional ER and Golgi gatekeepers?

488 - What is the molecular basis of gatekeeper selectivity for cargo receptors?

489 - How are ER and Golgi gatekeepers coordinated to regulate the export of a specific

490 receptor?

491 - Is GPCR oligomerization a more general mechanism controlling receptor export to 492 the cell surface?

493 - How are PRAFs and more generally Yips themselves regulated? How this type of 494 regulation might be connected with receptor function and regulation?

495 - Are there pathological conditions associated with mutations or quantitative changes 496 of receptor gatekeepers?

497 - Can diseases associated with impaired cell surface targeting of GPCR variants be 498 explained by enhanced interaction between receptors and ER or Golgi gatekeepers?

499 - Is it possible to target receptor - gatekeeper interfaces with chemical compounds to 500 enhance receptor export and treat diseases? 


\section{Highlights}

Functional $\mathrm{GABA}_{B}$ receptors are obligate hetero-dimers of the GB1 and GB2 subunits

The agonist binding GB1 is retained inside the cells in the absence of association with GB2

GB2 competitively releases GB1 from PRAF2, a specific, endoplasmic reticulumresident gatekeeper

The stoichiometry of PRAF2 relatively to GB1 and GB2 is a key parameter for $\mathrm{GABA}_{\mathrm{B}}$ function in vivo 
Figure 1
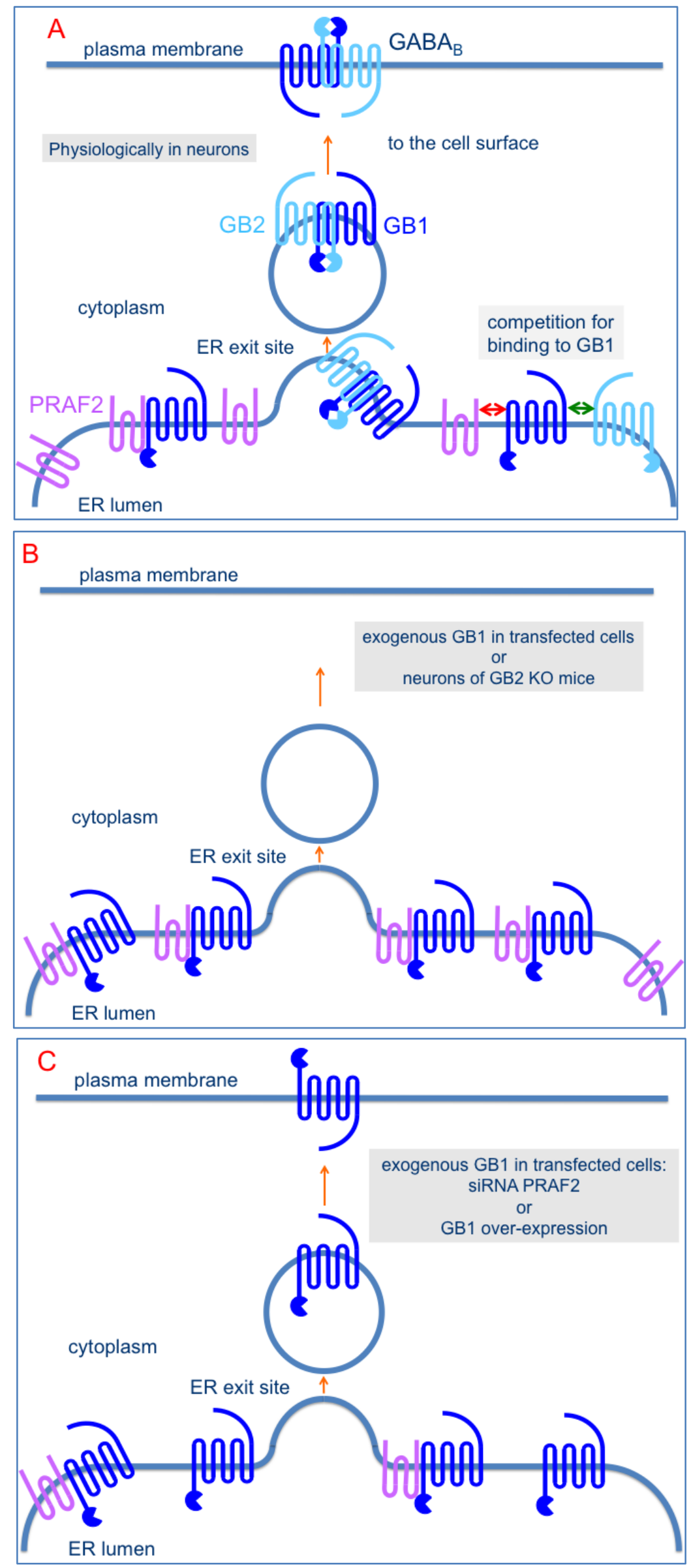

Figure 1 
Figure 2
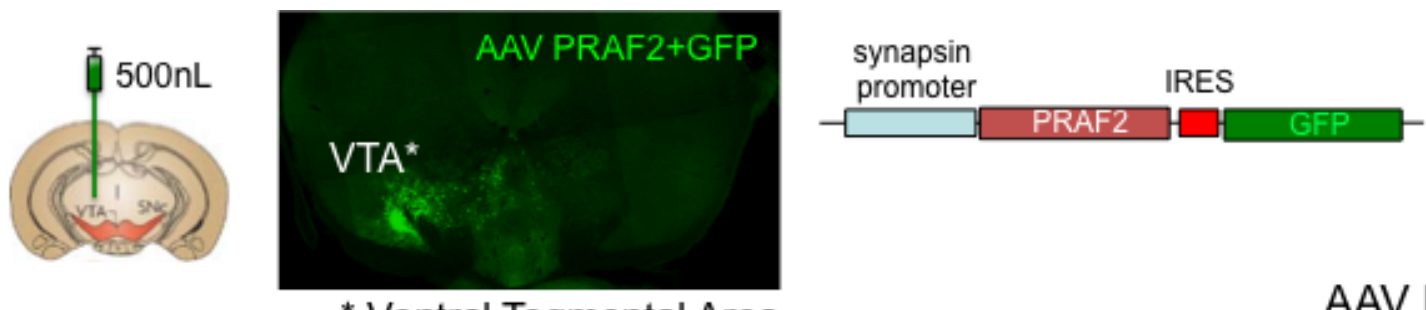

${ }^{*}$ Ventral Tegmental Area
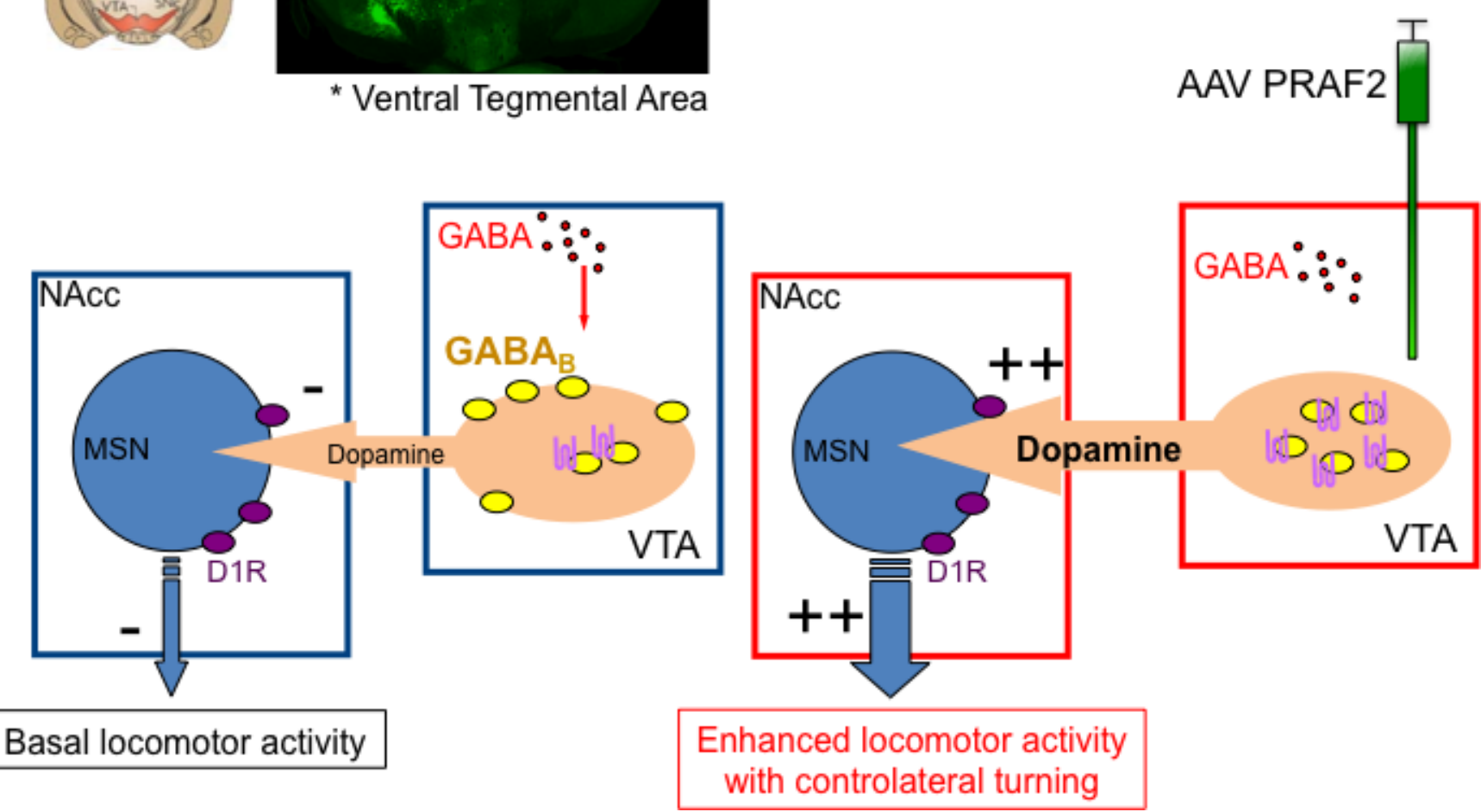

Figure 2 